\title{
Bridging the Translation Gap: From Dementia Risk Assessment to Advice on Risk Reduction
}

\author{
K.J. Anstey ${ }^{1}$, R. Eramudugolla, D.E. Hosking ${ }^{1}$, N.T. Lautenschlager ${ }^{2,3}$, R.A. Dixon ${ }^{4}$

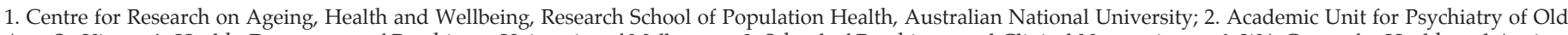

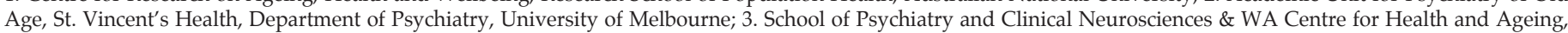
University of Western Australia; 4. Department of Psychology, University of Alberta, Canada

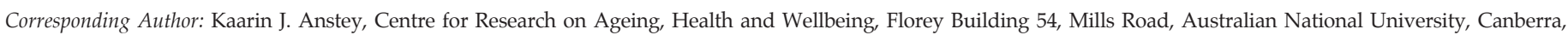
ACT 0200, Australia Tel: (612) 61258410; Fax: (612) 61251558; Email: kaarin.anstey@anu.edu.au

\begin{abstract}
Dementia risk reduction is a global health and fiscal priority given the current lack of effective treatments and the projected increased number of dementia cases due to population ageing. There are often gaps among academic research, clinical practice, and public policy. We present information on the evidence for dementia risk reduction and evaluate the progress required to formulate this evidence into clinical practice guidelines. This narrative review provides capsule summaries of current evidence for 25 risk and protective factors associated with AD and dementia according to domains including biomarkers, demographic, lifestyle, medical, and environment. We identify the factors for which evidence is strong and thereby especially useful for risk assessment with the goal of personalising recommendations for risk reduction. We also note gaps in knowledge, and discuss how the field may progress towards clinical practice guidelines for dementia risk reduction.
\end{abstract}

Key words: Risk factor, Alzheimer disease, cognitive decline, prevention, risk assessment.

\section{Introduction}

$\mathrm{U}$ ntil effective therapeutics for Alzheimer's disease (AD) are available, secondary prevention is an important focus for health professionals in relation to dementia. Secondary prevention encompasses risk reduction in those with multiple established risk factors for dementia, as well as interventions to slow progression of cognitive decline in adults with cognitive impairment or minor neurocognitive disorders (1). The development and integration of risk assessment and clinical risk management for $\mathrm{AD}$ and dementia is emerging rapidly in the research field, with the development of online risk assessment tools, education programs and lifestyle interventions $(2,3)$. However, for this research to have substantial public policy improvements, it must be translated, tested, and evaluated in clinical and community settings. At present, risk management, including risk reduction and protection elevation, is the only available approach with potential for a large impact on the projected rates of dementia given population aging. The emerging focus on the development and implementation of efficacious dementia risk reduction protocols is consistent with best practice as applied to other chronic conditions or diseases and it has the advantages of being relatively inexpensive and translatable.

The development of clinical practice guidelines and policies relating to dementia prevention requires a sound evidence base on risk and protective factors, as well as a framework for applying advice to relevant populationsubgroups. This review provides an overview of 25 risk and protective factors for late-life AD and dementia and then describes how this knowledge may inform the development of risk assessment procedures and risk management targets in the context of clinical practice guidelines.

\section{Multidomain assessment of risk and protective factors for AD}

Many studies report research on risk and protective factors in relation to $\mathrm{AD}$, while some only report results in relation to a general outcome of dementia. In this article we consult published meta-analyses and largescale cohort studies to note which risk and protective factors have been linked to $A D$ specifically or to $A D$ and dementia more generally. There are fewer reports relating risk and protective factors specifically to vascular cognitive impairment because the prevalence of distinct vascular dementia $(\mathrm{VaD})$ is lower than $\mathrm{AD}$ : hence, this review does not address that outcome. There is often both vascular and Alzheimer pathology contributing to neurocognitive disorders. Notably, a lack of precision in diagnosis is a feature of the observational research on which much of the risk and protective factors have been based.

Established risk and protective factors for $\mathrm{AD}$ and dementia come from several domains, exacerbating the complexity of conducting a thorough risk 
assessment. That some factors may operate interactively or synergistically increases the need for careful interpretation of risk profiles. Assessing multiple domains of risk simultaneously permits an evaluation of overall risk profile, including the development of panels of risk factors, risk factor composite scores, and interactions among two or more synergistic risk factors. Systematic review and meta-analysis of the current state of knowledge of risk factors for dementia is beyond the scope of a single article. We present a summary of the current knowledge in this area, drawing on key review articles, meta-analyses $(1,4-8)$ and individual papers, with more detail provided on recent findings on diet and dementia risk, which is an emerging area of interest.

Our framework for linking risk and protective factors to individual patient outcomes is depicted in Figure 1 (adapted from (9)). This figure shows the relationships between risk and protective factors for dementia, and clinical assessment goals. As depicted in the first column, there are five clusters of risk and protective factors, including biomarkers (not reviewed in this article), demographic factors, lifestyle, medical and environmental risk. The second column illustrates that these factors flow together in individual cases and likely interact (synergistically, interactively, complementary) in unique ways to lead to individualized outcomes. The third column identifies three general clusters of cognitive/clinical status outcomes, including relatively healthy brain and cognitive aging, typical non-demented cognitive trajectories, and cognitive impairment and dementia. Subsequently, the fourth column presents an associated direction of personalized consultation regarding risk-related recommendations. For healthy brain aging, advice will focus on sustained protective support and risk reduction. For typical or normative aging, advice should focus on risk reduction and increase in protective behaviors. For preclinical dementia or MCI, advice may focus on immediate risk control and perhaps reduction, especially targeting modifiable factors in the medical and lifestyle domains. Table 1 summarises the information on risk and protective factors as organized into the same demographic, lifestyle, medical and environmental domains.

\section{The role of biomarkers: Indicators of mechanisms}

Risk and protective factors exert detectable and potentially manageable influence on the course of neurodegenerative disease through relatively diffuse or as yet undetermined biological mechanisms. In some cases, biological markers (biomarkers) can be linked to somewhat more specific biological pathways associated with cognitive impairment, $\mathrm{AD}$, and dementia. It is likely that biomarkers will play an increasingly important role in risk assessment in the future (eg (10)). Given the heterogeneity of aetiologies, mechanisms and phenotypes of dementia, biomarkers and their pathways may be ultimately used in compiling risk profiles for groups or individuals. Notably, modifiable risk factors that interact with specific biomarkers offer specific opportunities for early alterations in the course of the disease. Although a review of biomarkers for $\mathrm{AD}$ is beyond the scope of this article, the information provided by some well-known and typically accessible biomarkers can provide crucial supplemental information for the overall dementia risk profile (11). However, it is known that at autopsy, a large minority of individuals who died without dementia have AD neuropathology $(12,13)$; hence, detection of disease processes does not necessarily mean that an individual will develop AD. This uncertainty does not change the need to target preventive strategies among at-risk individuals but indicates that individuals with biomarkers for AD may not necessarily express the clinical symptoms. (Autosomal mutations are an exception.) As with all diseases that have multiple risk factors, where prediction (prior to diagnosis) is never entirely accurate, and which develop after decades of gradual accumulation of pathology, a comprehensive risk appraisal is required.

Eventually, biomarkers of common pathogenic processes leading to brain ageing and concomitant Alzheimer pathology may provide a framework by which to organise risk and protective factors. For example, markers of inflammation are evident in a number of conditions that increase risk of $\mathrm{AD}$ including abdominal obesity, Type II diabetes and exposure to air pollution. However, most useful for present purposes would be information pertaining to genetic variants with known and elevated risk for AD. A recent large meta-analysis of genome-wide association studies in those of European ancestry found 11 new susceptibility loci for AD (14). The current state of knowledge indicates important supplemental information for constructing risk profiles could include (at least) APOE $\varepsilon 4$ status. For this article, we turn attention to risk and protective functions from the four domains of factors that operate through indirect (and often modifiable) pathways.

\section{The demographic domain}

Demographic risk factors include both modifiable and determinable non-modifiable characteristics, and enable profiling of population sub-groups at increased risk of dementia using population-level characteristics. Risk of $\mathrm{AD}$ and dementia strongly increases with chronological age (15), and in most countries is higher for women than men $(15,16)$. Low levels of formal school education increases the risk of $\mathrm{AD}$ and dementia (17). At present it is unknown whether increasing levels of education later in life confers the same protection as equivalent years of education obtained earlier in life. Higher levels of education appear to be associated with high level of cognitive function into late life, but not with reduced 
Table 1. Summary of findings on risk and protective factors for AD and dementia

\begin{tabular}{|c|c|c|c|c|}
\hline \multirow[b]{2}{*}{ Risk Factor } & \multirow[b]{2}{*}{ Meta-analyses } & \multicolumn{2}{|c|}{ Period of life affected by risk factor } & \multirow[b]{2}{*}{ Comments } \\
\hline & & Mid Life & Late Life & \\
\hline \multicolumn{5}{|l|}{ Demographic } \\
\hline Age & Yes $(15,16)$ & Yes & Yes & $\begin{array}{l}\text { Consistent finding of increasing prevalence and incidence of } \\
\mathrm{AD} \text { and dementia with age. }\end{array}$ \\
\hline Sex & Yes (16) & Yes & Yes & $\begin{array}{l}\text { Many studies find rates higher for females at older ages. It is } \\
\text { unclear how much this relates to greater longevity in women. }\end{array}$ \\
\hline Education & Yes (17) & Yes & Yes & $\begin{array}{l}\text { Reliable across multiple systematic reviews of high quality } \\
\text { cohort studies. May moderate effects of neuropathology on } \\
\text { cognition. RCTs not possible. }\end{array}$ \\
\hline Ethnicity/race & No & Yes & Yes & $\begin{array}{l}\text { Emerging evidence that } \mathrm{AD} \text { prevalence differs with } \\
\text { ethnicity, race and geographical location. Far more research } \\
\text { is required to quantify these effects and identify how risk } \\
\text { factors are moderated by ethnicity and race. }\end{array}$ \\
\hline \multicolumn{5}{|l|}{ Lifestyle } \\
\hline Physical activity & Yes (8) & insufficient evidence & Yes & $\begin{array}{l}\text { Few studies have used adequate measures of physical } \\
\text { activity. Studies also confounded by selection effects. }\end{array}$ \\
\hline Diet & Yes $(36,41)$ & Yes & Yes & $\begin{array}{l}\text { Evidence for protective effects of fish, and Mediterranean } \\
\text { diet. Small number of studies. Effect of moderate alcohol } \\
\text { may be confounded by selection factors. }\end{array}$ \\
\hline Smoking & Yes (47) & Yes & Yes & $\begin{array}{l}\text { Reliable across multiple cohort studies and supported by } \\
\text { cessation interventions. }\end{array}$ \\
\hline Mental activity & No & Yes & Yes & $\begin{array}{l}\text { Mixed findings from cohort studies. Few high quality RCTs. } \\
\text { Large RCT suggests short term benefits that do not impact } \\
\text { risk over } 5 \text { years. }\end{array}$ \\
\hline Social engagement & No & insufficient evidence & Yes & $\begin{array}{l}\text { Difficult to control for the effect of cognitive decline on social } \\
\text { engagement in late-life. }\end{array}$ \\
\hline \multicolumn{5}{|l|}{ Medical } \\
\hline $\begin{array}{l}\text { Hypertension/Hypoten- } \\
\text { sion }\end{array}$ & Yes (61) & Yes & Yes & Mixed results from systematic reviews of AD. \\
\hline Atrial Fibrillation & Yes (113) & insufficient evidence & Yes & Risk increased for all-cause dementia. \\
\hline Stroke & Yes (66) & insufficient evidence & Yes & Risk increased for both $\mathrm{AD}$ and $\mathrm{VaD}$. \\
\hline Diabetes and pre-diabetes & Yes (114) & Yes & Yes & $\begin{array}{l}\text { Reliable across multiple cohort studies for diabetes as a risk } \\
\text { for VaD and AD. Emerging consistent data for pre-diabetes. }\end{array}$ \\
\hline Bodyweight and adiposity & Yes $(71,115)$ & Yes & Yes & $\begin{array}{l}\text { Both high BMI and decline in BMI in mid-life related to } \\
\text { dementia risk. In late life }>60 \text { high BMI protective. }\end{array}$ \\
\hline Cholesterol & Yes (74) & Yes & $\begin{array}{l}\text { insufficient } \\
\text { evidence }\end{array}$ & Variable measures of cholesterol across different studies. \\
\hline Traumatic Brain Injury & No & Yes & $\begin{array}{l}\text { insufficient } \\
\text { evidence }\end{array}$ & $\begin{array}{l}\text { Mixed findings from cohort studies. Many studies have } \\
\text { inadequately defined } \mathrm{AD} \text { or } \mathrm{TBI} \text {, and used retrospective } \\
\text { designs. }\end{array}$ \\
\hline Depression & Yes $(78,116)$ & Yes & Yes & Late-life depression may represent a prodrome of AD. \\
\hline Homocysteine & Yes $(86,117)$ & insufficient evidence & Yes & $\begin{array}{l}\text { A causal relationship between } \mathrm{AD} \text { and homocysteine levels } \\
\text { is not supported. RCTs show no effect on dementia risk of } \\
\text { reducing homocysteine through B vitamin supplements. }\end{array}$ \\
\hline \multicolumn{5}{|l|}{ Medications } \\
\hline Statins & Yes $(118,119)$ & insufficient evidence & Yes & $\begin{array}{l}\text { Observational data suggest a neuroprotective effect, but } \\
\text { RCTs have shown inconsistent effects. }\end{array}$ \\
\hline Anti-hypertensives & Yes $(120,121)$ & insufficient evidence & Yes & $\begin{array}{l}\text { Antihypertensive treatments shown to reduce the risk } \\
\text { of all-cause dementia, vascular dementia and to benefit } \\
\text { overall cognition, although these effects differed by drug } \\
\text { class. Antihypertensive use did not decrease risk of } \mathrm{AD} \text {, } \\
\text { cognitive decline or cognitive impairment. }\end{array}$ \\
\hline Anti-inflammatories & Yes (122) & insufficient evidence & $\begin{array}{l}\text { insufficient } \\
\text { evidence }\end{array}$ & $\begin{array}{l}\text { Observational data suggest a protective effect especially in } \\
\text { long-term users. A single RCT showed no significant effect } \\
\text { on AD risk. }\end{array}$ \\
\hline
\end{tabular}




\begin{tabular}{|l|l|l|l|l|}
\hline HRT & Yes (123) & insufficient evidence & $\begin{array}{l}\text { insufficient } \\
\text { evidence }\end{array}$ & $\begin{array}{l}\text { An early meta-analysis indicated decreased risk for } \\
\text { dementia in HRT users. The risks and benefits of HRT to } \\
\text { women's health require further evaluation. }\end{array}$ \\
\hline Anticholinergics & No & insufficient evidence & Yes & $\begin{array}{l}\text { Converging evidence as reversible cause of cognitive decline } \\
\text { in older adults. }\end{array}$ \\
\hline $\begin{array}{l}\text { Environment } \\
\text { Pesticide }\end{array}$ & No & insufficient evidence & Yes & $\begin{array}{l}\text { Consistent across small number of multiple cohort studies } \\
\text { for increased risk of PD and AD. }\end{array}$ \\
\hline Air-pollution & No & Yes & Yes & $\begin{array}{l}\text { Few prospective studies with dementia as an outcome, but } \\
\text { effects found for cognition. }\end{array}$ \\
\hline
\end{tabular}

rate of decline (18). In a related area, results have been inconsistent regarding bilingualism as a possible protective factor against late onset dementia. Although some evidence has suggested bilinguals have a delayed onset of dementia due to increased cognitive reserve (19) others have studied samples including monolinguals and bilinguals and found no difference in rate of cognitive decline or onset of dementia (20). A demographic characteristic that is rarely discussed in detail is race. It appears that specific racial and ethnic groups have higher rates of AD risk factors. Some groups may have a higher or lower risk in relation to specific biological risk factors such as APOE (21), with evidence the APOE $\varepsilon 4$ allele does not influence dementia progression in sub-Saharan Africans. Among developing countries, prevalence estimates of dementia for adults aged 65 and older are higher in certain Asian and Latin American countries, but are low (1-3\%) in India and sub-Saharan Africa (22). A recent study has shown that adults of Hispanic origin have earlier onset of dementia than nonHispanics, adjusting for APOE genotype (23). However, not enough data are available to produce quantitative pooled estimates of these effects. Far more research is required to evaluate how risk profiles vary by race and ethnicity, which may potentially explain significant variation in the strength of specific genetic, medical or lifestyle factors as risk or protective in relation to AD. However, there is now sufficient evidence to incorporate age and sex into risk scores for incident dementia.

\section{Lifestyle domain}

Lifestyle-related risk factors for $\mathrm{AD}$ and dementia have been the focus of much recent research due to their modifiability. The prime lifestyle factors for which there is a body of evidence in relation to dementia risk include physical activity, diet, smoking, cognitive engagement and social engagement.

\section{Physical activity}

There is consistent evidence that physical activity is associated with reduced AD and dementia risk, with higher levels of activity associated with the lowest risk (24). The benefits of physical activity for cognitive health appear to accumulate over the life course. For example, higher fitness levels in young adulthood has been linked with better cognitive outcomes in mid-adulthood (25), and better midlife fitness has been linked to reduced risk of late-life dementia (26). However, there is also evidence that taking up physical activity in old age can still impact positively on cognitive and functional performance (27). The effect of physical activity on brain ageing and neurodegeneration is also corroborated by neuroimaging studies and intervention studies $(28,29)$ and intervention durations of 6 months and longer are reported as being more effective than shorter durations (30). To date, the majority of positive findings of trials are from samples of cognitively healthy older adults. A much smaller number of trials to date focused on trials with at-risk populations, especially those with subjective memory complaints or mild cognitive impairment. Some studies have reported significant benefits in the cognitive domains of attention, executive functions and memory $(31,32)$; however, other reports did not demonstrate such benefits (33). The inconsistency in results highlights the need for more high-quality later randomized controlled trials and a number of those are currently under way.

\section{Dietary components and dietary patterns}

The dietary component with the strongest link to $\mathrm{AD}$ and dementia risk reduction is oily fish, with three or more servings a week being associated with lower risk $(34,35)$. Studies have consistently shown a relationship between low levels of alcohol intake (rather than abstinence) and reduced risk of $\mathrm{AD}$, dementia and cognitive decline $(36,37)$. However, it is possible that this association partly reflects selection bias. Specifically, abstainers may include former heavy drinkers, with resultant poor cognitive and general health, and heavy drinkers are less likely to persist in longitudinal studies (38) . There is some evidence that n-3 fatty acids (39) and Vitamin B may be beneficial for those in the early stages of decline although a recent meta-analysis of 11 trials found no cognitive benefits associated with Vitamin B supplementation (40).

The Mediterranean diet (MeDi) (Figure 2) was shown in a meta-analysis of five studies conducted with over 2-8 years follow-up to be associated with $33 \%$ reduced risk of 
cognitive impairment (MCI or AD) (41) and adherence to the MeDi has also been associated with reduced cognitive decline $(42,43)$. The cognitive benefits of the MeDi were confirmed by a 5-year randomised controlled trial (RCT). Those who consumed a MeDi supplemented with extravirgin olive oil or mixed nuts had higher mean MiniMental State Examination (MMSE) scores and Clock Drawing Test scores than those who consumed a low fat control diet (44). The DASH diet (Dietary Approaches to Stop Hypertension) (45) includes whole grains, poultry, fish, and nuts and is reduced in saturated fats, red meats, sweets, and sugar-containing beverages. The two studies that have investigated associations between DASH dietary patterns and cognitive decline both found the DASH diet to be protective against cognitive decline (43, 46).

Figure 1. Model of Multidomain influences on major cognitive phenotypes in ageing including $\mathrm{AD}$ and dementia. Risk assessment and consultation goals are indicated for each phenotype

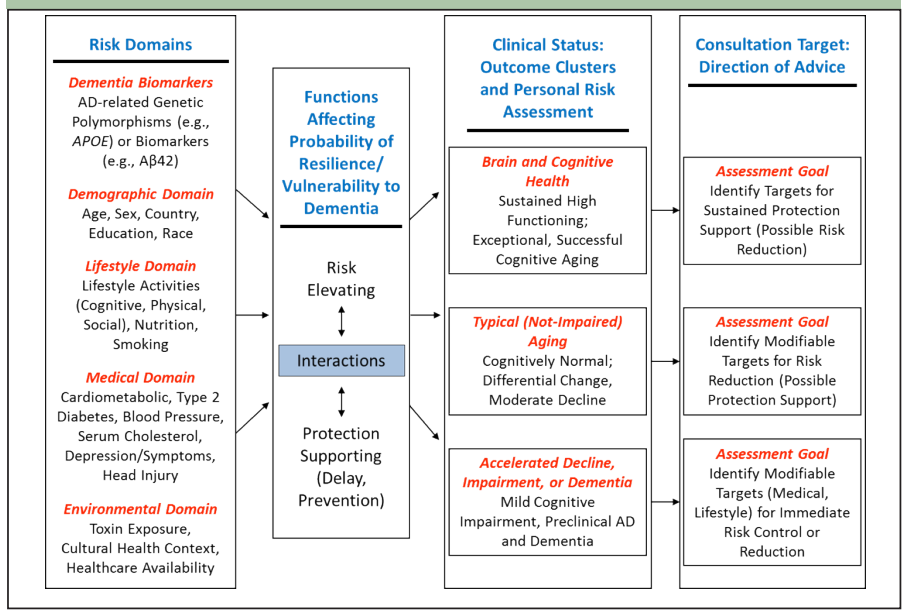

Adapted from Dolcos et al (2012)

\section{Smoking}

Smoking in late-life has been shown to increase the risk of $\mathrm{AD}, \mathrm{VaD}$ and dementia $(47,48)$ and it is inferred from this that smoking earlier in adulthood is also associated with increased risk, although specific data on this are presently lacking. Smoking cessation is associated with less late-life (over 70) cognitive decline and brain atrophy than continued smoking (49) providing strong support for advising patients to cease smoking even at older ages.

\section{Cognitive engagement}

Engaging in cognitively stimulating activities in late life (e.g., reading, playing puzzles and attending museums and concerts) is associated with a lower risk of $\mathrm{AD}$ and dementia $(50,51)$. However effective dosage and type of cognitive activity are not yet known, and to date, there is no reliable evidence for an effect of cognitive training programs on delaying dementia. Research on the benefits of cognitive engagement is often confounded, as individuals with higher initial cognitive ability also engage in more cognitively stimulating lifestyles.

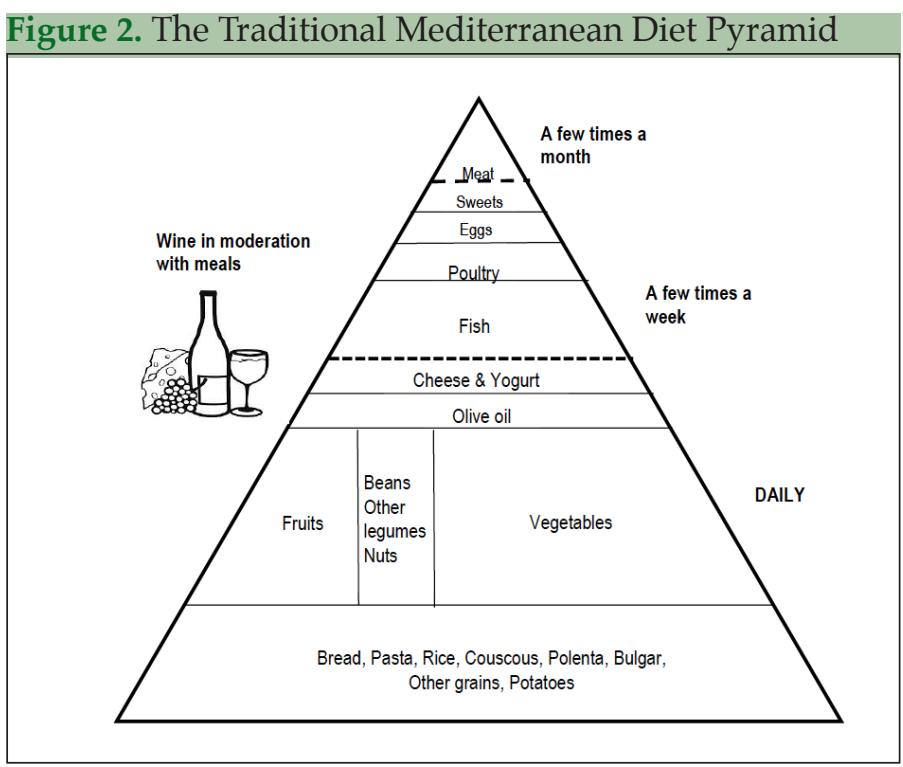

Adapted from Willett 1995 et al. (Copyright 1994 Oldways Preservation \& Exchange Trust)

\section{Social engagement}

There is consistent evidence that higher levels of social engagement are associated with reduced risk of $\mathrm{AD}$ and dementia $(52,53)$, even in adults with the APOE e4 genotype (54), and there is RCT evidence that it increases brain volume (55). Social engagement measures include different types of relationships, living arrangements, size and quantity of social networks and amount of social activities.

\section{Medical domain}

Cardiometabolic risk factors in midlife have been linked to late-life cognitive decline, $\mathrm{AD}$ and late-life dementia $(56,57)$ but late-life cardiometabolic risk factors have less clear associations with dementia. The link between abnormally high or low blood pressure in late life and dementia risk is inconsistent (58), with some evidence that low blood pressure may increase cognitive decline through reduced perfusion (59). While high blood pressure increases risk of stroke, and stroke is a strong risk factor for dementia (60), high blood pressure in late life has not been consistently linked with cognitive decline or AD. Findings relating blood pressure to risk of $\mathrm{AD}$ and dementia are complex, and influenced by methodological issues such as the length of follow up, whether or not treatment is evaluated, and whether trajectories are modelled that examine both increasing and decreasing hypertension at different stages of the 
adult life-course (58). Support has not been found in systematic reviews for a link between hypertension and $\mathrm{AD}$ (61). It is possible that the inconsistency associated with blood pressure and $\mathrm{AD}$ is due to the measure of blood pressure used in cohort studies. Peripheral hypertension is usually measured, and yet in old age, peripheral hypertension has a low correlation with central hypertension, which is the true risk factor for cerebrovascular changes and AD (62). In general, it appears that high blood pressure in midlife may represent a risk for dementia in later life (63). If untreated, hypertension in middle age that increases into old age may increase dementia risk, although a decline in blood pressure is seen in the period prior to the development of AD.

A recent systematic review of atrial fibrillation (AF) as a risk factor for cognitive impairment (defined as MMSE<24) or any type of dementia (DSM-IV criteria) identified an increased risk associated with AF both with and without history of stroke, despite study heterogeneity (64).

Stroke has also been considered as a risk factor for $\mathrm{AD}$ even after controlling for the presence of other cardiometabolic risk factors such as hypertension, diabetes and heart disease $(65,66)$. Individuals with a history of stroke had an earlier onset as well as a higher incidence of AD relative to those without a stroke history, although the risk was highest in those with recognized vascular risk factors. It is possible that a stroke may accelerate or bring above threshold the level of neuropathology and cognitive impairment required for progression to $\mathrm{AD}$ in those with mild or sub-clinical pathology (65). In terms of other forms of dementia and vascular dementia in particular, a meta-analysis of 30 studies (66) reported that even after adjusting for other vascular risk factors, recurrent stroke increases the prevalence of dementia, with a rise in incidence after each additional stroke, suggesting stroke contributes significantly to the pathology leading to dementia over and above existing cardiovascular risk.

There is consistent evidence that elevated blood glucose (including Type II diabetes) increases the risk for cognitive decline, AD and dementia (67), and that this risk is independent of other cardiometabolic risk factors associated with diabetes $(68,69)$. There is also emerging evidence that pre-diabetic and sub-clinical levels of high blood glucose also predict cognitive decline and dementia $(69,70)$ although there have been no meta-analyses of this association.

Obesity and being overweight during midlife has been associated with increased late-life $\mathrm{AD}$ and dementia risk (71) with midlife obesity conferring double the risk of late-life AD. The relationship between late-life obesity and dementia risk is unclear $(71,72)$ with the balance of evidence presently suggesting that it is not associated with increased risk. One study has shown that weight loss predicted AD similarly in overweight and normal weight adults, indicating that trajectory of weight loss rather than BMI was predictive of dementia in older adults (73).

High serum cholesterol during midlife is associated with elevated $\mathrm{AD}$ and dementia risk (74); however, this relationship is not consistently evident for high cholesterol in late life (75).

Systematic reviews have shown that clinically diagnosed depression and depressive symptoms, in both midlife and late-life, are each consistently associated with elevated risk of $\mathrm{AD}$, cognitive decline and dementia (76-78). In late-life, evidence suggests that late-onset depression may also represent a prodrome of $\mathrm{AD}(79)$. Altogether these findings suggest that screening for depression is an essential component of risk profiling for AD.

Head injury during adulthood is associated with increased $\mathrm{AD}$ and dementia risk, specifically where the injuries were moderate or severe and occurred frequently (80-82). Repetitive concussion and head injuries as experienced by boxers is also associated with risk of developing a distinct neurodegenerative syndrome (8385). Although not modifiable, information on history of head injury may contribute to an overall picture of a patient's accumulated lifetime exposure to risks for AD.

Elevated plasma homocysteine increases the risk of vascular disease and stroke (86) and has been associated, albeit inconsistently, with poorer cognitive performance and dementia risk (87). Homocysteine levels increase with age and are dependent on Vitamin B metabolism (86). A number of trials in older adults have tested whether lowering homocysteine by vitamin B supplementation slows cognitive decline (40). Those with MCI and higher initial baseline homocysteine levels demonstrated better cognitive and clinical outcomes (88) and reduced brain atrophy (89). Recent preliminary evidence also suggests that the impact of homocysteine on older-age cognition may be dependent on its interactive effects with cholesterol (90).

There is some evidence from observational studies that certain classes of drugs such as anti-hypertensives, statins (91, 92), non-steroidal anti-inflammatories (NSAIDS) (93) (but see (94)) and hormone replacement therapy (HRT) (95), are associated with reduced $\mathrm{AD}$ and dementia risk. However, RCTs are either lacking or, apart from some isolated findings, do not generally support dementia risk reduction through statin therapy (96), the use of antihypertensives (97), or anti-inflammatories (98). A recent follow-up of RCTs indicate that HRTs have a complex pattern of risks and benefits for women's health (99) and are thus not recommended for dementia prevention. One large study showed increased risk of dementia associated with NSAIDS (94). In one review of hypertensives, a significant effect (-18\% incidence) was found for diuretic or dihydropyridine calcium channel blockers as part of active treatment for hypertension, although the overall pooled effect of hypertensives was not significant (100). 
Therefore, at this point in time, while medication is recommended to treat medical conditions associated with risk of $\mathrm{AD}$, we lack high quality evidence of their role in prevention. On the other hand, the reduction in rates of dementia observed recently in several countries has been speculatively attributed in part to better management of cardiovascular risk factors, better health care and increased levels of education (101) .

Drugs with anticholinergic properties are used for treating common medical conditions such as asthma, urinary incontinence, seasonal allergies, insomnia, depression, and other psychiatric conditions $(102,103)$. Age-related decrease in cholinergic receptors and in the increase in blood-brain barrier permeability (102) increase the risk of anticholinergic medication causing cognitive impairment. The Adult Changes in Thought study found that a 10-year cumulative dose-response relationship was demonstrated between anticholinergic drug use and increased risk for all-cause dementia and AD. Associations remained robust across subgroup analyses and subclasses of anticholinergic medication use (103). These findings add weight to earlier clinical recommendations that elderly patients using anticholinergic medication should be monitored for cognitive dysfunction and if adverse effects are suspected, medications could be withdrawn (102).

\section{Environmental domain}

There is evidence for increased risk of dementia (Parkinson's Disease with Dementia, and Alzheimer's Disease and other dementias) in individuals exposed to very high levels of pesticides $(104,105)$. While there is insufficient data to date on the link between air pollution and dementia risk, there is some evidence high levels of air pollution is associated with greater cognitive impairment in older adults (106-108) and air pollution has been associated with AD neuropathology (108).

\section{Conclusion: From risk assessment to risk reduction}

This review has evaluated evidence pertaining to 25 factors that have been associated in epidemiological literature with increased risk of $\mathrm{AD}$ and dementia in some studies. Some of these factors are now considered uncontroversial risk or protective factors for AD (109) despite the lack of RCT evidence. The way in which knowledge about risk factors for $\mathrm{AD}$ and dementia is obtained does not map well onto the hierarchical model of the widely used GRADE system for ranking the quality of evidence. This is because most of the information on dementia risk is epidemiological and not experimental. However, clinical practice guidelines typically use systems such as GRADE in their development using consensus among experts. We argue that in the field of dementia prevention, it will be necessary to carefully consider the optimal methods of grading evidence so that routinely prioritising RCTs may not be the best approach. It is more appropriate that bodies of evidence are considered holistically or integratively (animal models, short-term RCTs, long term epidemiological studies, neuropathological evidence) in relation to putative risk factors and their mechanisms. Adopting rigorous yet realistic criteria is likely to be the most pragmatic approach to developing guidelines while evidence is still being collated and evaluated in this field.

Our review demonstrates that the multiple domains of risk and protection are populated by a variety of specific factors that independently or interactively may contribute to incident dementia in older adults. The body of evidence continues to grow and understanding of risk factors is becoming increasingly nuanced with (a) synergistic and modifier effects being increasingly addressed in observational research and (b) more specific (rather than global) questions being addressed in clinical trials. Broader questions that can now start to be addressed include consideration of the requirements to develop specific clinical practice guidelines for dementia prevention, and methods for evaluating risk assessment for $\mathrm{AD}$ and dementia.

To move this field towards evidence-based clinical practice guidelines, research needs to provide more specific information on the quantity or dose of factors that are required for protection. For example, specific prescriptions of physical activity, or specific dietary advice, should be further evaluated in trials. Recent findings from multidomain trials will be able to guide research and personal advice $(110,111)$. In some cases the qualitative types or range of activities that are protective is not known. For example, the value of brain training compared with a lifestyle of active reading has never been evaluated, and water-based physical activity has rarely been evaluated in relation to level and trajectory of cognitive function in aging. This lack of specific information reduces the clarity with which practical advice may be developed and distributed to individuals.

For risk factors such as blood glucose, more specific guidelines on levels of risk are required, as recent research shows that even within the normal range, variation in blood glucose is associated with future risk of dementia (70). Clinical practice guidelines also need to take account of the patient's age and life course, considering the cumulative or synergistic effects of risk factors on other risk factors and outcomes that may ultimately increase late-life dementia risk or protection. For example, obesity in young adulthood may increase the risk of Type II Diabetes in mid-adulthood which in turn increases the risk of dementia in late adulthood.

Risk assessment for AD is now possible using well researched questionnaires, medical tests, checklists and online tools. There are now tools available to address risk in a range of ages and circumstances, from the population 
level in middle age, through to risk among older adults with brain atrophy and impaired IADLs. Risk assessment tools provide clinicians with validated means of assessing risk or identifying areas where protection may be increased, when they are administered to the appropriate group.

There is not yet a standard practice in this field but the evidence is now strong enough to support personalized recommendations for risk reduction by increasing levels of education in young adulthood, increasing physical, cognitive and social activity throughout adulthood, reducing cardiovascular risk factors including diabetes in middle-age, through lifestyle and medication, treating depression, adopting a healthy diet and physical activity, avoiding pesticides and heavy air pollution and teaching avoidance of all potential dangers to brain health while enhancing potential protective factors.

Now that risk assessment for dementia is possible, researchers and policy makers can also start to identify markers of success in dementia prevention interventions. We have previously argued that risk reduction, as opposed to dementia prevention, is a more realistic and useful immediate goal when focussing on the majority of the population who are middle-aged and have no cognitive symptoms (112). At the individual level, risk reduction is the most meaningful outcome, as the time frames for dementia prevention are so long and it is not possible to estimate the true contribution of genetic risk factors at the individual level. At the population level, estimates of incidence and prevalence over decades remain the most objective measures of disease burden; however, there are other factors that may indicate success in prevention strategies. These include delaying the age of onset of dementia, slowing the progression of disease and reducing the overall health burden associated with dementia.

Acknowledgements: KJA is funded by NHMRC Research Fellowship \# 1002560. RAD is supported in part by a Canada Research Chair (Tier 1) and a grant from the National Institutes of Health (NIA; R01 AG008235). The research is supported by the Dementia Collaborative Research Centres. DH is funded by Australian Research Council Centre of Excellence in Population Ageing Research (\#CE110001029).

Conflict of interests: Authors have no conflicts of interest to declare.

\section{References}

1. Fratiglioni L, Qiu C. Prevention of cognitive decline in ageing: dementia as the target, delayed onset as the goal. Lancet Neurol. 2011;10:778-9.

2. Barnes DE, Covinsky KE, Whitmer RA, Kuller LH, Lopez OL, Yaffe K. Commentary on «Developing a national strategy to prevent dementia: Leon Thal Symposium 2009.» Dementia risk indices: A framework for identifying individuals with a high dementia risk. Alzheimer's \& Dementia 2010;6:13841.

3. Solomon A, Mangialasche F, Richard E, Andrieu S, Bennett DA, Breteler M, et al. Advances in the prevention of Alzheimer's disease and dementia. J Intern Med. 2014;275:229-50.

4. Qiu C, Kivipelto M, von Strauss E. Epidemiology of Alzheimer's disease: occurrence, determinants, and strategies toward intervention. Dialogues Clin Neurosci. 2009;11:111-28.

5. Ritchie K, Carriere I, Ritchie CW, Berr C, Artero S, Ancelin ML. Designing prevention programmes to reduce incidence of dementia: prospective cohort study of modifiable risk factors. BMJ. 2010;341:c3885.

6. Barnes DE, Covinsky KE, Whitmer RA, Kuller LH, Lopez OL, Yaffe K.
Predicting risk of dementia in older adults: The late-life dementia risk index. Neurol. 2009;73:173-9.

7. Barnes DE, Yaffe K. The projected effect of risk factor reduction on Alzheimer's disease prevalence. Lancet Neurol. 2011;10:819-28.

8. Williams JW, Plassman BL, Burke J, Benjamin S. Preventing Alzheimer's disease and cognitive decline. Evid Rep Technol Assess (Full Rep). 2010:1727.

9. Dolcos S, MacDonald SW, Braslavsky A, Camicioli R, Dixon RA. Mild cognitive impairment is associated with selected functional markers: integrating concurrent, longitudinal, and stability effects. Neuropsychology. 2012;26:209-23.

10. Waragai M, Hata S, Suzuki T, Ishii R, Fujii C, Tokuda T, et al. Utility of SPM8 plus DARTEL (VSRAD) ombined with magnetic resonance spectroscopy as djunct techniques for screening and predicting dementia due to Alzheimer's disease in clinical practice. J Alzheimers Dis. 2014.

11. Hall JR, Wiechmann AR, Johnson LA, Edwards M, Barber RC, Cunningham $R$, et al. The impact of APOE status on relationship of biomarkers of vascular risk and systemic inflammation to neuropsychiatric symptoms in Alzheimer's disease. J Alzheimers Dis. 2014

12. Katzman R, Terry R, DeTeresa R, Brown T, Davies P, Fuld P, et al. Clinical, pathological, and neurochemical changes in dementia: a subgroup with preserved mental status and numerous neocortical plaques. Ann Neurol. 1988;23:138-44.

13. Stern Y. Cognitive reserve and Alzheimer disease. Alzheimer Dis Assoc Disord. 2006;20:S69-74

14. Lambert J-C, Ibrahim-Verbaas CA, Harold D, Naj AC, Sims R, Bellenguez C, et al. Meta-analysis of 74,046 individuals identifies 11 new susceptibility loci for Alzheimer's disease. Nat Genet. 2013;45:1452-8.

15. Jorm AF, Dear KB, Burgess NM. Projections of future numbers of dementia cases in Australia with and without prevention. Aust N Z J Psychiatry. 2005;39:959-63.

16. Alzheimer Disease International. World Alzheimer's Report. In: Prince M, Jackson J, editors. London: King's College London; 2009.

17. Caamaño-Isorna F, Corral M, Montes-Martínez A, Takkouche B. Education and dementia: a meta-analytic study. Neuroepidemiology. 2006;26:226-32.

18. Zahodne LB, Glymour MM, Sparks C, Bontempo D, Dixon RA, MacDonald SW, et al. Education does not slow cognitive decline with aging: 12-year evidence from the Victoria longitudinal study. J Int Neuropsychol Soc. 2011;17:1039-46.

19. Bialystok E, Craik FI, Luk G. Bilingualism: consequences for mind and brain. Trends Cogn Sci. 2012;16:240-50.

20. Zahodne LB, Schofield PW, Farrell MT, Stern Y, Manly JJ. Bilingualism does not alter cognitive decline or dementia risk among Spanish-speaking immigrants. Neuropsychology. 2014;28:238-46.

21. Murrell JR, Price B, Lane KA, Baiyewu O, Gureje O, Ogunniyi A, et al Association of apolipoprotein E genotype and Alzheimer disease in African Americans. Arch Neurol. 2006;63:431-4.

22. Kalaria RN, Maestre GE, Arizaga R, Friedland RP, Galasko D, Hall K, et al. Alzheimer's disease and vascular dementia in developing countries: prevalence, management, and risk factors. Lancet Neurol. 2008;7:812-26.

23. Fitten LJ, Ortiz F, Fairbanks L, Bartzokis G, Lu P, Klein E, et al. Younger age of dementia diagnosis in a Hispanic population in southern California. Int J Geriatr Psychiatry. 2014.

24. Hamer M, Chida Y. Physical activity and risk of neurodegenerative disease: a systematic review of prospective evidence. Psychol Med. 2009;39:3-11.

25. Zhu N, Jacobs DR, Jr., Schreiner PJ, Yaffe K, Bryan N, Launer LJ, et al Cardiorespiratory fitness and cognitive function in middle age: The CARDIA Study. Neurol. 2014;82:1339-46.

26. Defina LF, Willis BL, Radford NB, Gao A, Leonard D, Haskell WL, et al. The association between midlife cardiorespiratory fitness levels and later-life dementia: a cohort study. Ann Intern Med. 2013;158:162-8

27. Almeida OP, Khan KM, Hankey GJ, Yeap BB, Golledge J, Flicker L. 150 minutes of vigorous physical activity per week predicts survival and successful ageing: a population-based 11-year longitudinal study of 12201 older Australian men. Br J Sports Med. 2014;48:220-5.

28. Erickson KI, Raji CA, Lopez O, Becker JT, Rosano C, Newman AB, et al Physical activity predicts gray matter volume in late adulthood. Neurology. 2010;75:1415-22.

29. Erickson KI, Voss MW, Prakash RS, Basak C, Szabo A, Chaddock L, et al. Exercise training increases size of hippocampus and improves memory. Proc Natl Acad Sci USA. 2011;108:3017-22.

30. Lautenschlager NT. Physical activity and cognition in older adults with mild cognitive impairment and dementia. Neurodegen Dis Management. 2013;3:211-8.

31. Lautenschlager NT, Cox KL, Flicker L, Foster JK, van Bockxmeer FM, Xiao J, et al. Effect of physical activity on cognitive function in older adults at risk for Alzheimer disease: a randomized trial. JAMA. 2008;300:1027-37.

32. Baker LD, Frank LL, Foster-Schubert K, Green PS, Wilkinson CW, McTiernan A, et al. Effects of aerobic exercise on mild cognitive impairment: a controlled trial. Arch Neurol. 2010;67:71-9.

33. Scherder EJ, Van Paasschen J, Deijen JB, Van Der Knokke S, Orlebeke JF, Burgers I, et al. Physical activity and executive functions in the elderly with 
mild cognitive impairment. Aging Ment Health. 2005;9:272-80.

34. Barberger-Gateau P, Raffaitin C, Letenneur L, Berr C, Tzourio C, Dartigues JF, et al. Dietary patterns and risk of dementia: the Three-City cohort study. Neurol. 2007;69:1921-30.

35. Huang TL, Zandi PP, Tucker KL, Fitzpatrick AL, Kuller LH, Fried LP, et al. Benefits of fatty fish on dementia risk are stronger for those without APOE \&4. Neurology. 2005;65:1409-14.

36. Anstey KJ, Mack HA, Cherbuin N. Alcohol consumption as a risk factor for dementia and cognitive decline: meta-analysis of prospective studies. Am J Geriatr Psychiatry. 2009;17:542-55.

37. Peters R, Peters J, Warner J, Beckett N, Bulpitt C. Alcohol, dementia and cognitive decline in the elderly: a systematic review. Age Ageing. 2008;37:505-12.

38. Roizen R, Fillmore K, Chikritzhs T, Stockwell T. Light-to-moderate drinking and dementia risk: the former drinkers problem re-visited. Addict Research Theory. 2013;21:181-93.

39. Freund-Levi Y, Eriksdotter-Jonhagen M, Cederholm T, Basun H, FaxenIrving G, Garlind A, et al. Omega-3 fatty acid treatment in 174 patients with mild to moderate Alzheimer disease: OmegAD study: A randomized doubleblind trial. Arch Neurol. 2006;63:1402-8.

40. Clarke R, Bennett D, Parish S, Lewington S, Skeaff M, Eussen SJ, et al. Effects of homocysteine lowering with B vitamins on cognitive aging: meta-analysis of 11 trials with cognitive data on 22,000 individuals. Am J Clin Nutr. 2014;100:657-66.

41. Singh B, Parsaik AK, Mielke MM, Erwin PJ, Knopman DS, Petersen RC, et al. Association of Mediterranean diet with mild cognitive impairment and Alzheimer's disease: a systematic review and meta-analysis. J Alzheimers Dis. 2014;39:271-82.

42. Lourida I, Soni M, Thompson-Coon J, Purandare N, Lang IA, Ukoumunne $\mathrm{OC}$, et al. Mediterranean diet, cognitive function, and dementia: a systematic review. Epidemiology. 2013;24:479-89.

43. Tangney CC, Hong L, Wang Y, Barnes L, Schneider JA, Bennett DA, et al. Relation of DASH- and Mediterranean-like dietary patterns to cognitive decline in older persons. Neurology. 2014.

44. Martínez-Lapiscina EH, Clavero P, Toledo E, Estruch R, Salas-Salvadó J, San Julián B, et al. Mediterranean diet improves cognition: the PREDIMEDNAVARRA randomised trial. J Neurol, Neurosurg \& Psychiatry. 2013.

45. Vogt TM, Appel LJ, Obarzanek EVA, Moore TJ, Vollmer WM, Svetkey LP, et al. Dietary Approaches to Stop Hypertension: rationale, design, and methods. J Am Diet Assoc. 1999;99:S12-S8.

46. Wengreen H, Munger RG, Cutler A, Quach A, Bowles A, Corcoran C, et al. Prospective study of Dietary Approaches to Stop Hypertension- and Mediterranean-style dietary patterns and age-related cognitive change: the Cache County study on memory, health and aging. Am J Clin Nutr. 2013;98:1263-71.

47. Anstey KJ, von Sanden C, Salim A, O'Kearney R. Smoking as a risk factor for dementia and cognitive decline: a meta-analysis of prospective studies. Am J Epidemiol. 2007; 166:367-78.

48. Peters R, Poulter R, Warner J, Beckett N, Burch L, Bulpitt C. Smoking, dementia and cognitive decline in the elderly: a systematic review. BMC Geriatr. 2008;8:36.

49. Almeida OP, Garrido GJ, Alfonso H, Hulse G, Lautenschlager NT, Hankey GJ, et al. 24-month effect of smoking cessation on cognitive function and brain structure in later life. Neuroimage. 2011;55:1480-9.

50. Wilson RS, Scherr PA, Schneider JA, Tang Y, Bennett DA. Relation of cognitive activity to risk of developing Alzheimer disease. Neurology. 2007;69:1911-20.

51. Valenzuela M, Brayne C, Sachdev P, Wilcock G, Matthews F. Cognitive lifestyle and long-term risk of dementia and survival after diagnosis in a multicenter population-based cohort. Am J Epidemiol. 2011;173:1004-12.

52. Bassuk SS, Glass TA, Berkman LF. Social disengagement and incident cognitive decline in community-dwelling elderly persons. Ann Intern Med. 1999;131:165-73.

53. Fratiglioni L, Wang HX, Ericsson K, Maytan M, Winblad B. Influence of social network on occurrence of dementia: a community-based longitudinal study. Lancet. 2000;355:1315-9.

54. Ferrari C, Xu WL, Wang HX, Winblad B, Sorbi S, Qiu C, et al. How can elderly apolipoprotein E $\varepsilon 4$ carriers remain free from dementia? Neurobiol Aging. 2013;34:13-21.

55. Mortimer JA, Ding D, Borenstein AR, DeCarli C, Guo Q, Wu Y, et al. Changes in brain volume and cognition in a randomized trial of exercise and social interaction in a community-based sample of non-demented Chinese elders. J Alzheimers Dis. 2012;30:757-66.

56. Kivipelto M, Helkala EL, Laakso MP, Hanninen T, Hallikainen M, Alhainen $\mathrm{K}$, et al. Midlife vascular risk factors and Alzheimer's disease in later life: longitudinal, population based study. BMJ. 2001;322:1447-51.

57. Fratiglioni L, Qiu C. Prevention of common neurodegenerative disorders in the elderly. Exp Gerontol. 2009;44:46-50.

58. Joas E, Backman K, Gustafson D, Ostling S, Waern M, Guo X, et al. Blood pressure trajectories from midlife to late life in relation to dementia in women followed for 37 years. Hypertension. 2012;59:796-801.

59. Glodzik L, Rusinek H, Pirraglia E, McHugh P, Tsui W, Williams S, et al.
Blood pressure decrease correlates with tau pathology and memory decline in hypertensive elderly. Neurobiol Aging. 2014;35:64-71.

60. Dregan A, Wolfe CD, Gulliford MC. Does the influence of stroke on dementia vary by different levels of prestroke cognitive functioning?: A cohort study. Stroke. 2013;44:3445-51.

61. Power MC, Weuve J, Gagne JJ, McQueen MB, Viswanathan A, Blacker D. The association between blood pressure and incident Alzheimer disease: A systematic review and meta-analysis. Epidemiology. 2011;22:646-59.

62. Palatini P, Casiglia E, Gasowski J, Gluszek J, Jankowski P, Narkiewicz K, et al. Arterial stiffness, central hemodynamics, and cardiovascular risk in hypertension. Vascular health and risk management. 2011;7:725-39.

63. Barnes DE, Yaffe K. The projected effect of risk factor reduction on Alzheimer's disease prevalence. Lancet Neurol. 2011.

64. Kwok CS, Loke YK, Hale R, Potter JF, Myint PK. Atrial fibrillation and incidence of dementia: a systematic review and meta-analysis. Neurology. 2011;76:914-22.

65. Honig LS, Ming-Xin T, Albert S, Costa R, Luchsinger JA, Manly JJ, et al. Stroke and the risk of Alzheimer disease. Arch Neurol. 2003;60:1707-12.

66. Pendlebury ST, Rothwell PM. Prevalence, incidence, and factors associated with pre-stroke and post-stroke dementia: a systematic review and metaanalysis. Lancet Neurol. 2009;8:1006-18.

67. Cheng G, Huang CT, Deng H, Wang H. Diabetes as a risk factor for dementia and mild cognitive impairment: a meta-analysis of longitudinal studies. Intern Med J. 2012;42:484-91.

68. Biessels GJ, Staekenborg S, Brunner E, Brayne C, Scheltens P. Risk of dementia in diabetes mellitus: a systematic review. Lancet Neurol. 2006;5:6474.

69. Lu FP, Lin KP, Kuo HK. Diabetes and the risk of multi-system aging phenotypes: a systematic review and meta-analysis. PLOS-One. 2009;4.

70. Crane PK, Walker R, Hubbard RA, Li G, Nathan DM, Zheng H, et al. Glucose levels and risk of dementia. N Engl J Med. 2013;369:540-8.

71. Anstey KJ, Cherbuin N, Budge M, Young J. Body mass index in midlife and late-life as a risk factor for dementia: a meta-analysis of prospective studies. Obes Rev. 2011.

72. Sabia S, Kivimaki M, Shipley M, Marmot M, Singh-Manoux A. Body mass index over the adult life course and cognition in late midlife: the Whitehall II cohort study. Am J Clin Nutr. 2009;89:601-7.

73. Power BD, Alfonso H, Flicker L, Hankey GJ, Yeap BB, Almeida OP. Changes in body mass in later life and incident dementia. Int Psychogeriatr. 2013;25:467-78.

74. Anstey KJ, Lipnicki DM, Low LF. Cholesterol as a risk factor for dementia and cognitive decline: a systematic review of prospective studies with metaanalysis. Am J Geriatr Psychiatry. 2008;16:343-54.

75. Di Paolo G, Kim T-W. Linking lipids to Alzheimer's disease: cholesterol and beyond. Nat Rev Neurosci. 2011;12:285-96.

76. Ownby RL, Crocco E, Acevedo A, John V, Loewenstein D. Depression and risk for Alzheimer disease: systematic review, meta-analysis, and metaregression analysis. Arch Gen Psychiatry. 2006;63:530-8.

77. Barnes DE, Yaffe K, Byers AL, McCormick M, Schaefer C, Whitmer RA. Midlife vs late-life depressive symptoms and risk of dementia: differential effects for Alzheimer disease and vascular dementia. Arch Gen Psychiatry. 2012;69:493-8.

78. Diniz BS, Butters MA, Albert SM, Dew MA, Reynolds CF. Latelife depression and risk of vascular dementia and Alzheimer's disease: systematic review and meta-analysis of community-based cohort studies. Br J Psychiatry. 2013;202:329-35.

79. Lee GJ, Lu PH, Hua X, Lee S, Wu S, Nguyen K, et al. Depressive symptoms in mild cognitive impairment predict greater atrophy in Alzheimer's diseasetelated regions. Biol Psychiatry. 2012;71:814-21.

80. Fleminger S, Oliver DL, Lovestone S, Rabe-Hesketh S, Giora A. Head injury as a risk factor for Alzheimer's disease: the evidence 10 years on; a partial replication. J Neurol Neurosurg Psychiatry. 2003;74:857-62.

81. Mayeux R, Ottman R, Maestre GE, Ngai BS, Tang MX, Ginsberg H, et al. Synergistic effects of traumatic head injury and apolipoprotein-e4 in patients with Alzheimer's disease. Neurology. 1995;45:555-7.

82. Plassman BL, Havlik RJ, Steffens DC, Helms MJ, Newman TN, Drosdick D, et al. Documented head injury in early adulthood and risk of Alzheimer's disease and other dementias. Neurology. 2000;56:1158-66.

83. Jordan BD. The clinical spectrum of sport-related traumatic brain injury. Nat Rev Neurol. 2013;9:222-30.

84. Smith DH, Johnson VE, Steward W. Chronic neuropathologies of single and repetitive TBI: substrates of dementia? Nat Rev Neurol. 2013:211-21.

85. Stern RA, Danshvar DH, Baugh CM, Seichepine DR, Montenigro PH, Riley DO, et al. Clinical presentation of chronic traumatic encephalopathy. Neurology. 2013;81:1122-9.

86. The Homocysteine Studies Collaboration. Homocysteine and risk of ischemic heart disease and stroke. JAMA. 2002;288:2015-22.

87. Ho RCM, Cheung MWL, Fu E, Win H, Zaw MH, Ng A, et al. Is high homocysteine level a risk factor for cognitive decline in elderly? A systematic review, meta-analysis, and meta-regression. Am J Geriatr Psychiatry. 2011;19:607-17.

88. de Jager CA, Oulhaj A, Jacoby R, Refsum H, Smith AD. Cognitive and 
clinical outcomes of homocysteine-lowering B-vitamin treatment in mild cognitive impairment: a randomized controlled trial. Int J Geriatr Psychiatry. 2012;27:592-600.

89. Smith AD, Smith SM, de Jager CA, Whitbread P, Johnston C, Agacinski G, et al. Homocysteine-lowering by $\mathrm{B}$ vitamins slows the rate of accelerated brain atrophy in mild cognitive impairment: A randomized controlled trial. PLOSOne. 2010.

90. Cheng Y, Jin Y, Unverzagt FW, Su L, Yang L, Ma F, et al. The relationship between cholesterol and cognitive function is homocysteine-dependent. Clin Interv Aging. 2014;9:1823-9.

91. Song Y, Nie H, Xu Y, Zhang L, Wu Y. Association of statin use with risk of dementia: a meta-analysis of prospective cohort studies. Geriatr Gerontol Int. 2013;13:817-24.

92. Wong WB, Lin VW, Boudreau D, Devine EB. Statins in the prevention of dementia and Alzheimer's disease: A meta-analysis of observational studies and an assessment of confounds. Pharmacoepidemiol Drug Saf. 2013;22:34558.

93. Etminan M, Gill S, Samii A. Effect of non-steroidal anti-inflammatory drugs on risk of Alzheimer's disease: systematic review and meta-analysis of observational studies. BMJ. 2003;327:128.

94. Breitner JC, Haneuse SJ, Walker R, Dublin S, Crane PK, Gray SL, et al. Risk of dementia and $\mathrm{AD}$ with prior exposure to NSAIDs in an elderly communitybased cohort. Neurology. 2009;72:1899-905.

95. Zandi PP, Carlson MC, Plassman BL. Hormone replacement therapy and incidence of Alzheimer disease in older woment: the Cache County study. JAMA. 2002;288:2123-9.

96. Scott HD, Laake K. Statins for the prevention of Alzheimer's disease and dementia. Cochrane database of systematic reviews. 2009;CD003160:1-11.

97. McGuiness B, O'Hare J, Craig D, Bullock R, Maloug R, Passmore P. Cochrane review on 'Statins for the treatment of dementia'. Int J Geriatr Psychiatry. 2013;28:119-26

98. Breitner JC, Baker LD, Montine TJ, Meinert CL, Lyketsos C, Ashe KH, et al. Extended results of the Alzheimer's disease anti-inflammatory prevention trial. Alzheimer's \& Dementia. 2011;7:402-11.

99. Manson JE, Chlebowski RT, Stefanick ML, et al. Menopausal hormone therapy and health outcomes during the intervention and extended poststopping phases of the women's health initiative randomized trials. JAMA. 2013;310:1353-68.

100. Staessen JA, Thijs L, Richart T, Odili AN, Birkenhager WH. Placebocontrolled trials of blood pressure-lowering therapies for primary prevention of dementia. Hypertension. 2011;57:e6-7.

101. Matthews FE, Arthur A, Barnes LE, Bond J, Jagger C, Robinson L, et al. A two-decade comparison of prevalence of dementia in individuals aged 65 years and older from three geographical areas of England: results of the Cognitive Function and Ageing Study I and II. Lancet. 2013.

102. Campbell N, Boustani M, Limbil T, Ott C, Fox C, Maidment I, et al. The cognitive impact of anticholinergics: A clinical review. Clin Interv Aging. 2009;4:225-33

103. Gray SL, Anderson ML, Dublin S, et al. Cumulative use of strong anticholinergics and incident dementia: A prospective cohort study. JAMA Int Med. 2015;175:401-7.

104. Hayden KM, Norton MC, Darcey D, Ostbye T, Zandi PP, Breitner JC, et al. Occupational exposure to pesticides increases the risk of incident AD: the Cache County study. Neurology. 2010;74:1524-30.

105. Priyadarshi A, Khuder SA, Schaub EA, Shrivastava S. A meta-analysis of Parkinson's disease and exposure to pesticides. Neurotoxicology. 2000;21:435-40

106. Chang K-H, Chang M-Y, Muo C-H, Wu T-N, Chen C-Y, Kao C-H. Increased risks of dementia in patients exposed to nitrogen dioxide and carbon monoxide: A population-based retrospective cohort study. PLOS-One. 2014.

107. Brown TP, Rumsby PC, Capleton AC, Rushton L, Levy LS. Pesticides and Parkinson's Disease: is there a link? Environ Health Perspect. 2006;114:156-64.

108. Calderon-Garciduenas L, Kavanaugh M, Block M, D'Angiulli A, DelgadoChavez R, Torres-Jardon R, et al. Neuroinflammation, hyperphosphorylated tau, diffuse amyloid plaques, and down-regulation of the cellular prion protein in air pollution exposed children and young adults. J Alzheimers Dis. 2012;28:93-107.

109. Norton S, Matthews FE, Barnes DE, Yaffe K, Brayne C. Potential for primary prevention of Alzheimer's disease: an analysis of population-based data. Lancet Neurol. 2014;13:788-94.

110. Ngandu T, Lehtisalo J, Solomon A, Levalahti E, Ahtiluoto S, Antikainen R, et al. A 2 year multidomain intervention of diet, exercise, cognitive training, and vascular risk monitoring versus control to prevent cognitive decline in at-risk elderly people (FINGER): a randomised controlled trial. Lancet. 2015.

111. Vellas B, Carrie I, Gillette-Guyonnet S, Touchon J, Dantoine T, Dartigues JF, et al. MAPT study: a multidomain approach for preventing Alzheimer's disease: design and baseline data. Journal for the Prevention of Alzheimer's Disease. 2014;1:13-22.

112. Anstey KJ, Bahar-Fuchs A, Herath P, Rebok GW, Cherbuin N. A 12-week multidomain intervention versus active control to reduce risk of Alzheimer's disease: study protocol for a randomized controlled trial. Trials. 2013;14:60-

113. Kalantarian S, Stern TA, Mansour M, Ruskin JN. Cognitive impairment associated with atrial fibrillation a meta-analysis. Ann Intern Med. 2013;158:338-46.

114. Gudala K, Bansal D, Schifano F, Bhansali A. Diabetes mellitus and risk of dementia: A meta-analysis of prospective observational studies. Journal of Diabetes Investigation. 2013;4:640-50.

115. Loef M, Walach $H$. Midlife obesity and dementia: meta-analysis and adjusted forecast of dementia prevalence in the United States and China. Obesity. 2013;21:E51-E5.

116. Gao Y1 HC, Zhao K, Ma L, Qiu X, Zhang L, Xiu Y, Chen L, Lu W, Huang C, Tang Y, Xiao Q. Depression as a risk factor for dementia and mild cogniive impairment: a meta-analysis of longitudinal studies. Int J Geriatr Psychiatry. 2013;28:441-9.

117. Ho RCM, Cheung MWL, Fu E, Win $\mathrm{H}$, Zaw MH, A. N, et al. Is high homocysteine level a risk factor for cognitive decline in elderly? A systematic review, meta-analysis, and meta-regression. Am J Geriatr Psychiatry. 2011;19:607-17.

118. Zhou B, Teramukai S, Fukushima M. Prevention and treatment of dementia or Alzheimer's disease by statins: a meta-analysis. Dement Geriatr Cogn Disord. 2007;23:194-201.

119. Swiger KJ, Manalac RJ, Blumenthal RS, Blaha MJ, Martin SS. Statins and cognition: A systematic review and meta-analysis of short- and long-term cognitive effects. Mayo Clinic Proceedings. 2013;88:1213-21.

120. Levi Marpillat N, Macquin-Mavier I, Tropeano AI, Bachoud-Levi AC, Maison P. Antihypertensive classes, cognitive decline and incidence of dementia: a network meta-analysis. J Hypertens. 2013;31:1073-82.

121. Chang-Quan H, Hui W, Chao-Min W, Zheng-Rong W, Jun-Wen G, YongHong $\mathrm{L}$, et al. The association of antihypertensive medication use with risk of cognitive decline and dementia: a meta-analysis of longitudinal studies. Int J Clin Pract. 2013;65:1295-305.

122. Wang J, Tan L, Wang HF, Tan CC, Meng XF, Wang C, et al. Antiinflammatory drugs and risk of Alzheimer's disease: an updated systematic review and meta-analysis. J Alzheimers Dis. 2014.

123. LeBlanc ES, Janowsky J, Chan BKS, Nelson HD. Hormone replacement therapy and cognition: systematic review and meta-analysis. JAMA. 2001;285:1489-99. 